\title{
Problems with a renal replacement programme in a developing country
}

\author{
S.O. McLigeyo, L.S. Otieno, D.M.W. Kinuthia, S.K. Ongeri, F.K. Mwongera \\ and S.G. Wairagu
}

Renal Unit, Kenyatta National Hospital, Nairobi, Kenya

\begin{abstract}
Summary: Since August 1984 patients with end-stage renal disease in Kenya have been started on haemodialysis with a view to renal transplantation. In a two year period (August 1984-August 1986) 77 patients mean age 29.6 years ( 49 males), have been dialysed. The mean duration on dialysis prior to death or transplantation was 2.9 months (range 1 day to 11 months).

Fifty patients (65\%) died while on dialysis, including 2 who had had unsuccessful transplantation. Fourteen patients were still on dialysis, 11 had discharged themselves to peripheral hospitals for conservative management, and 2 had had successful renal transplantation.

The possible causes of this abysmal experience include admission of critically ill patients, shortage of trained staff, over-dependence on arteriovenous shunts for vascular access, lack of centralization of patient management, recurrent shortage of essențial equipment and reagents and a slow pace of transplantation.
\end{abstract}

\section{Introduction}

Regular haemodialysis programmes are expensive and might drain a proportionately high portion of the health budget in countries with limited resources. This is probably the major reason why such centres have not found a place in most developing countries. ${ }^{1}$

The success of maintenance dialysis in the treatment of end-stage renal disease is measured by the survival of patients and their quality of life. Most reports on these aspects have, as expected, come from developed countries where maintenance dialysis has been in use since the early 1960 s.

In Kenya, haemodialysis equipment has been available since $1972 .^{2}$ However, between that time and 1980 haemodialysis was carried out irregularly and was specifically meant for patients with acute renal failure in whom recovery was anticipated.

In the period beginning August 1984, haemodialysis has been carried out regularly at Kenyatta National Hospital. ${ }^{3}$ This followed the installation of 25 Gambro type haemodialysis machines in the renal unit early in 1984. The machines were part of a commodity aid from West Germany given to the Kenya Government and the renal unit where haemodialysis is being carried out was built by the government of Kenya.

Correspondence: S.O. McLigeyo, M.B., Ch.B., M.Med., c/o Dr J.L. Anderton, Nuffield Transplant Unit, Western General Hospital, Crewe Road, Edinburgh EH4 24U, UK. Accepted: 29 July 1987

\section{Patients and methods}

Between August 1984 and August 1986 a total of 77 patients (49 males) were dialysed. The majority were between 10 and 39 years and the mean age was 29.6 years.

Chronic glomerulonephritis accounted for the largest number, $34(44.4 \%)$, followed by hypertension, $16(20.8 \%)$.

Table I shows the total duration on dialysis. The mean duration was 2.9 months with a range of 1 day to 11 months. The mean number of hours of dialysis was 109.2 hours, with a range of 30 minutes to 395 hours. Vascular access has been mainly by arteriovenous shunts with only 4 of the 77 patients having had functioning fistulae.

From the beginning of August 1984, the Gambro machines with their parallel flow dialysers have been used exclusively.

The water used for dialysis underwent a process of softening, sedimention, filtration and reverse osmosis before being pumped to the continuous

Table I Number of patients dialysed and duration of their dialysis

\begin{tabular}{lllll}
\hline & \multicolumn{4}{c}{ Duration of dialysis (months) } \\
\cline { 2 - 5 } & $0-2$ & $3-5$ & $6-8$ & $9-11$ \\
\hline $\begin{array}{l}\text { No. of patients } \\
\text { \% of total }\end{array}$ & 42 & 20 & 9 & 6 \\
\hline
\end{tabular}

(C) The Fellowship of Postgraduate Medicine, 1988 
proportioning system which used a fixed proportioning pump to mix liquid concentrate with the water to produce the final dialysate as required, generally in $1 / 34$ proportion. The dialysate solute concentration for all patients was: sodium. $138.0 \mathrm{mmol} / \mathrm{l}$; potassium, $3.0 \mathrm{mmol} / 1$, calcium, $1.75 \mathrm{mmol} / 1$, magnesium, $1.0 \mathrm{mmol} / \mathrm{l}$; chloride, $108.5 \mathrm{mmol} / \mathrm{l}$; acetate, $38.0 \mathrm{mmol} / \mathrm{l}$; and glucose, $3.0 \mathrm{~g} / \mathrm{l}$.

The initial one or two dialyses, in all patients, were of short duration (2-3 hours) to avoid dialysis disequilibrium. Thereafter patients underwent thrice-weekly 4-hour dialyses, if in hospital, or twice-weekly 6-hour dialyses, if coming for dialysis from home.

Emergency dialysis was carried out mostly on patients who developed pulmonary oedema in the interdialytic period.

All patients came to the renal unit for dialysis and thereafter went back to the general wards or home.

The blood flow rate during most of the dialyses has been 200 to $250 \mathrm{ml} / \mathrm{min}$. The transmembrane pressure (ultrafiltration or hydrostatic pressure) has been personalized according to the individual patient's need, that is, the degree of fluid overload.

In all the dialyses heparin infusion at a rate of 500 units/hour has been used. Serum electrolytes have been determined at the beginning of every dialysis.

\section{Results}

\section{Blood pressure}

Before dialysis treatment was started, all the patients had significant hypertension, that is a blood pressure above $160 / 90 \mathrm{mmHg}$. Forty nine per cent had a diastolic blood pressure higher than $120 \mathrm{mmHg}$. One month after dialysis treatment was started reasonable blood pressure control was achieved in most patients. Three months after dialysis treatment, no patient had a diastolic pressure above $120 \mathrm{mmHg}$ and $76 \%$ were considered normotensive. At 6 months $20 \%$ of the patients were still hypertensive and required hypotensive drug therapy.

\section{Blood transfusion requirement}

Patients were transfused when the haemotocrit fell to below $21 \%$ or if it was higher but the patient was symptomatic. The requirements for blood transfusion varied from patient to patient but averaged approximately 2 units of whole blood per month.

\section{Biochemical analysis}

The endogenous creatinine clearance on starting maintenance haemodialysis was less than $5 \mathrm{ml} / \mathrm{min}$ in 21 patients, between 5 and $10 \mathrm{ml} / \mathrm{min}$ in 22 patients, and no clearances were available in 34 patients. The plasma creatinine levels prior to starting dialysis varied between 0.5 and $1.8 \mathrm{mmol} / 1$. with a mean of $0.77-0.052 \mathrm{mmol} / \mathrm{l}$ ( \pm s.e.m.). The blood urea nitrogen levels varied between 20 and $116 \mathrm{mmol} / \mathrm{l}$, mean $58.5 \pm 5.6 \mathrm{mmol} / \mathrm{l}$. The mean serum calcium level was $1.84 \pm 0.07 \mathrm{mmol} / 1$ while the mean phosphate levels were $1.6 \pm 0.14 \mathrm{mmol} / 1$.

Following one month of dialysis the corresponding mean serum levels of creatinine blood urea nitrogen, calcium and phosphate $(\mathrm{mmol} / \mathrm{l})$ were $0.250 \pm 0.031,14.7 \pm 0.22,2.2 . \pm 0.03,1.4 \pm 0.16$. At three months of dialysis the corresponding figures were $0.260 \pm 0.022, \quad 10.3 \pm 0.40, \quad 2.2 \pm 0.11$ and $1.3 \pm 0.21$.

\section{Arteriovenous shunts}

The arterial cannulae life averaged 1.8 months for 77 patients (42 replacements in 73 patient months). The venous cannulae life averaged 1.2 months $(55$ replacements); 120 shunt infections were seen, rate of one infection per 7.4 patients weeks. Staphy lococcus aureus was responsible for $62.5 \%$ of the infections.

\section{Hepatitis}

HBsAg testing by counterimmunoelectrophoresis has been in use all through. Six patients have been found positive for HBsAg pre-dialysis. Three patients of the 30 patients who have had dialysis for more than 4 months have converted from the HBsAg negative status to a positive status. Two patients and one member of the dialysis staff have developed clinically evident hepatitis.

\section{Rehabilitation}

The degree of rehabilitation has been difficult to assess in our patients. This is because all our patients have had dialysis as inpatients, except 8 who have had twice-weekly 6-hour dialysis from home, but even these have had repeated admissions because of problems related to the arteriovenous shunts.

\section{Dialysis deaths}

The number and causes of dialysis deaths are shown in Table II. Fifty patients $(65 \%)$ died while on dialysis, including 2 who had had unsuccessful 
Table II Number of patients and causes of dialysis deaths

\begin{tabular}{lc}
\hline \multicolumn{1}{c}{ Causes of death } & Number of patients \\
\hline $\begin{array}{l}\text { Cardiac failure with pulmonary } \\
\text { oedema }\end{array}$ & 20 \\
Uraemia with electrolyte & 7 \\
imbalance & 6 \\
Septicaemia & 5 \\
Neurological (disequilibrium & \\
syndrome and intracranial & \\
haemorrhage) & 4 \\
Sudden death & 3 \\
Pulmonary embolism & 3 \\
Pericardial effusion with & \\
tamponade & 2 \\
Cancer & \\
\hline
\end{tabular}

transplantations. The commonest cause of death was cardiac failure with pulmonary oedema. Seventeen patients died within a month, 21 patients between 1 and 3 months, 9 between 4 and 60 months and 3 between 7 and 12 months.

\section{Discussion}

Maintenance haemodialysis and renal transplant facilities are available in only three hospital units in Kenya, a country with an estimated population of 20 million. All these units are situated within the capital city. The incidence of end-stage renal disease in the country is estimated at 90 per million population per year, higher than that reported in some developed and developing countries ${ }^{4}$ and thus any renal replacement programme with tangible goals would have to take this into account.

Age, a criterion no longer tenable in developed countries, ${ }^{5}$ is of great significance in developing countries when selecting patients for renal replacement therapy as evidenced by the large number of young people suffering from end-stage renal disease in our patient population and that in other developing countries. ${ }^{4,6}$

It would appear from our two years' observations that we have had some success with blood pressure and biochemical control, but our one year survival rate of $35 \%$ is lower than that reported in some developing countries ${ }^{6}$ and in most developed countries in Europe ${ }^{7-10}$ and America ${ }^{11}$ in the last decade. The factors responsible for this high mortality are many. Our patients were often critically ill at the time of admission into the programme, a factor which is common in other developing countrics and in other medical conditions. In developing countries, patients often report to medical centres in advanced stages of illness due to inadequacy of medical facilities, lack of adequate transportation and to a certain extent due to ignorance. Furthermore our management of patients with end-stage renal disease has not been centralized. Patients come to the renal unit for dialysis and later go back to the general wards where a limited number of staff catering for several other patients with various ailments have to put up with the fluid, electrolyte and dietary management of these patients. This factor has accounted for the high incidence of cardiac failure and pulmonary oedema as a cause of death in our patients. It is noteworthy that ischaemic heart disease has not been a major problem contrary to what is reported in developed countries. ${ }^{9110}$ Recurrent shortage of essential equipment and reagents has had its role in our poor performance. Patients have had to miss or have inadequate dialyses on this account. In addition we have had a shortage of trained staff to man the renal unit. The few that are available have, in addition to running the renal unit, to take part in the management of patients with other ailments in the general medical wards. This has resulted in the unit not being continuously operational thus making emergency dialysis impossible. In addition, back-up peritoneal dialysis in these situations has been inadequate because these have had to be carried out in the general medical wards where a limited number of staff have a large number of patients under their care.

Vascular access is another area where there have been problems. We have depended on arteriovenous shunts excessively, contrary to what is practised elsewhere. This has resulted in several complications including exhaustion of access sites and being unable to institute emergency dialysis. The above dependence has been due to some of the factors alluded to above.

When regular haemodialysis was started at Kenyatta National Hospital for the treatment of end-stage renal disease, it was envisaged that its success would depend on a successful renal transplantation programme. However, our transplantation programme has not been very successful as evidenced by only two successful transplants in two years. This has rapidly led to a saturation of dialysis facilities and exhaustion of recurrent expenditure in the unit. The factors responsible for this slow pace of transplantation have included; total dependence on live related kidney donors at the expense of cadaveric kidneys, and the expense involved in the pre- and post-operative care amongst other things alluded to earlier.

In conclusion, the success of a renal replacement programme in a developing country would entail 
starting small manageable units with well trained staff. However due to the large number of patients suffering from end-stage renal disease, selection criteria would pose several ethical problems.

\section{References}

1. Abu-asha, H., Ibrahim, A., Salih, A.M. \& Beleil, O.M. Experience with renal allotransplantation. Case (report. Sudan Med J 1982, 18, 69-74.

2. Amolo, M.O., Abdullah, M.S., Otieno, L.S. \& Mwachandi, L.N. Haemodialysis at the Kenyatta National Hospital Intensive Care Unit. 1973-1980. Medicom 1983, 5: 37-39.

3. McLigeyo, S.O. Haemodialysis at Kenyatta National Hospital - a retrospective and prospective study. A thesis submitted in part fulfilment for the degree of Master of Medicine (Internal Medicine) at the University of Nairobi (119 pages).

4. Abdulla, K. Chronic renal failure in Northern Iraq. Iraq Med J 1979, 27: 43-46.

5. Walker, P.J., Ginn, H.E., Johnson, H.K. et al. Longterm haemodialysis for patients over 50 . Geriatrics, 1976, 13: 55-61.

6. Abdulla, K. Survival rates of patients on maintenance haemodialysis in Mosul, Iraq. Dial Transplant 1986, 15: $327-333$.

\section{Acknowledgements}

We thank all staff of the renal unit who have taken care of the patients under difficult conditions, and Mrs Gladys Okoola for secretarial assistance.

7. Gurland, H.J., Brunner, F.P.V., Dehn, H. et al. Combined report on regular dialysis and $\vec{\circ}$ transplantation in Europe. Proc Eur Dial Transplant Assoc Eur Ren Assoc 1973, 10: 17-57.

8. Gurland, H.J., Brunner, F.P., Chantler, C et al. Combined report on regular dialysis and transplantation in Europe. Proc Eur Dial Transplant Assoc Eur Ren Assoc 1976, 13: 3-9.

9. Henari, F.Z., Gower, P.E., Curtis, J.R. et al. Survival in 200 patients treated by haemodialysis and renal transplantation. Br Med J 1977, 1: 409-413.

10. Brynger, H., Brunner, F.P., Chantler, C. et al. Combined report on regular dialysis and transplantation in Europe. Proc Eur Dial Transplant Assoc Eur Ren Assoc 1980, 17: 4-86.

11. Friedman, E.A. Experience with maintenance haemodialysis. Patient survival. Nephron 1972, 9: 86-91. 